\title{
Study of Some Agricultural Crop Production Planning Condition through Fuzzy Multi-Objective Linear Programming Mathematical Model
}

\author{
Neela Patel ${ }^{1}$, Manish Thaker $^{2}$, Chandrika Chaudhary ${ }^{3}$ \\ ${ }^{1}$ Research Scholar, Pacific University Udaipur, Rajasthan, India \\ manas1708[at]yahoo.com \\ ${ }^{2}$ M. G. Science Institute, Ahmedabad, Gujarat, India \\ mbthaker2768[at]gmail.com \\ ${ }^{3}$ Research Scholar, Pacific University Udaipur, Rajasthan, India \\ chandrika_m71[at]yahoo.co.in
}

\begin{abstract}
Present study is an application of fuzzy optimization technique in agricultural planning particularly for farmers of Patan district, North Gujarat, India. Generally the crop planning problem is formulated as linear programming problem but in real situation there are many uncertain factors in agricultural production planning problems. Therefore future profit for crops is imprecise and uncertain. In this article an attempt is made to formulate a model for crop planning.
\end{abstract}

Keywords: Agricultural crops, Fuzzy Multi-Objective liner programming mathematical Model, Patan district

\section{Introduction}

Agriculture plays vital role in the Indian economy. India's geographical condition is unique for agriculture because it provides many favorable conditions. There are plain areas, fertile soil, long growing season and wide variation in climatic condition. Apart from unique geographical conditions, India has been consistently making innovative efforts by using science and technology to increase production. In agricultural production planning problems major objective is to maximize the profit under the minimum investment with some other constrains. An important issue in this problems is to optimize the objectives, based on one or multi-objective optimization, one or more goal to be considered. These problems of allocation of land for different crops, maximization of production of crops, maximization of profit are addressed in agricultural management system. Maximization of crop production can't guarantee the maximization of profit. Profit or loss is also depending on fluctuating demand and cost for the particular crop. Also agriculture is a process that, at any moment of time associated with the issue of risk, and there is no certainty. So the maximization of profit turns out to be fuzzy multi-objective decision making problem.

\section{Literature Review}

Fuzzy mathematical programming has been investigated and developed in several research studies. One of the important early contributions in fuzzy programming was given by Zimmermann [1] and [2]. In fuzzy multi-objective programming, Sakawa et al. [3] have presented an interactive fuzzy approach for multi-objective linear programming problems. One of the main approaches in dealing with fuzzy models is the possibility theory. The basic work in possibility theory was introduced by Dubois and Prade [4]. Their work has presented the foundation of the possibility programming approach, which has been applied to fuzzy linear single objective and multiobjective programming [5] and [6]
For agricultural production where uncertainty and vagueness effect the profit directly or indirectly, several researchers such as Slowinski [4], Sinha et al.[5], Sher and Amir[6], Sumpsi et al [7], Saraker et al[8], Pal and Moitra [9], Vasant [10], Biswas and Pal [11] used fuzzy goal programming techniques for farm planning problems. Lodwick et al. [12] made a comparison of fuzzy stochastic and deterministic method in a case of crop planning problem followed by a study of Itoh and Ishii [14] based on possibility measure. Itoh et al. [13] considered a problem of crop planning under uncertainty assuming profit coefficients are discrete random variables and proposed a model to obtain a maximum and minimum value of gains for decision maker. Sakawa and Yano[16], Chanas[17] used various types of membership functions for obtaining compromise solution. Anjali Garg, Shiva Raj Singh[15]provided a procedure to solve MOLP using Max Min approach to build up the member ship function and stated that it provides superior results.

\section{Study Area}

Patan district is located at $20^{\circ} 41^{\prime}$ to $23^{\circ} 55^{\prime}$ North Latitude and $71^{\circ} 31^{\prime}$ to $72^{\circ} 20^{\prime}$ East Latitude in western India. Patan district is surrounded by Banaskantha District, Desert of Kutch, some part of Surendranagar District and Mahesana District.

Total geographical area of the district is about 5.66 lakhs hectares. $70 \%$ of the geographical area is under cultivation in the district. Economy of the district mainly depends on agriculture, as 63.9 percent workers are engaged in primary sector.Net sown area of the district is about 3.93 lakh hectare and gross sown area is about 4.86 lakh hectares. The major crops cultivated in the district are castor, mustard and cotton. Also other crops grown are cumin, bajara, wheat, juwar and fennel. In some areas pulses like mung, tur, gram and vegetables are cultivated in the district. Depletion of water table, Deterioration of soil and water conditions due to salinity ingress, irregularity of rainfall, recurrent droughts/ scarcity is the major factors that have impeded agricultural productivity in the Patan district. The purpose of applying 


\section{International Journal of Science and Research (IJSR) \\ ISSN (Online): 2319-7064}

Index Copernicus Value (2013): 6.14 | Impact Factor (2015): 6.391

the techniques discussed in this paper is to achieve the best model for crop cultivation planning.

\section{Methodology}

First we introduce basic terms and definitions related to the paper and then mathematical formulation of the problems and finally the conclusion of the studies

1) Multi Objective linear programming problem:

In general, a multi objective optimization problem with $\mathrm{k}$ objectives, $\mathrm{n}$ variables and $\mathrm{p}$ constraints is as:

$$
\begin{gathered}
\operatorname{Max}\left\{Z_{1}, Z_{2}, \ldots \ldots, Z_{K}\right\} \\
\text { Such that } \\
\operatorname{Aj}(X) \leq b \ldots \ldots j=1,2, \ldots, p \\
X=\left\{x_{1}, x_{2}, \ldots \ldots, x_{n}\right\}, \\
x_{i} \geq 0, i=1,2, \ldots \ldots . n
\end{gathered}
$$

2) Fuzzy Multi Objective linear programming problem:

$$
\begin{aligned}
& \operatorname{MaxZ}_{1}(x)=\sum_{j=1}^{n} C_{1 j} x_{j} \\
& \operatorname{MaxZ}_{2}(x)=\sum_{j=1}^{n} C_{2 j} x_{j} \\
& -\operatorname{MaxZ}_{p}(x)=\sum_{j=1}^{n} C_{p j} x_{j} \\
& p=1,2,3, \ldots \ldots \ldots, m .-\cdots
\end{aligned}
$$

Subject to $x \in X,\left\{X \in R^{n}\right\} / A x \leq b, x \geq 0$

Where $x$ is a $n$-dimensional vector of decision variable.

$Z_{1}(x), Z_{2}(x), \ldots \ldots, Z_{p}(x)$ are $p$ distinct linear objective functions of the decision variable $x$

$C_{i j}$ is the cost factor vector,

$i=1,2, \ldots, m j=1,2, \ldots \ldots ., n$

$A$ is $m \times n$ constraint matrix.

$b$ is $m$ dimensionsl vector of total resources available.

To find decision vector $x$,

$$
\ni Z_{p}(x) \geq Z_{p}\left(x^{*}\right) \text { For } \forall p
$$

Where $Z_{p}\left(x^{*}\right)$, for $\forall p$ is our corresponding goal \& all objective functions are to be maximized.

Objective functions of equation (I) are to be fuzzy constraints.

If the tolerances of fuzzy constraints are given then a feasible solution set is characterized by its membership functions

$$
\mu_{A}(x)=\min \left\{\mu_{1}(x), \mu_{2}(x), \ldots \ldots, \mu_{p}(x)\right\}
$$

The solution can be obtained by solving the problem of maximizing $\mu_{A}(x)$ subject to $x \in X$.

i.e. $\operatorname{Max}\left(\operatorname{Min}_{p} \mu_{p}(x)\right)$ such that $x \in X$.

Let $\gamma=\operatorname{Min}_{p} \mu_{p}(x)$ be the overall satisfactory level of compromise then we get the equivalent model

$$
\operatorname{Max} \gamma
$$

Such that $\gamma \leq \mu_{p}(x)$ for $\forall p, x \in X$

Here membership functions of objective function is estimated by obtaining pay off matrix of positive ideal solution and assume that membership functions are of the type non decreasing linear or hyperbolic etc.

\section{Algorithm}

In this section, by using of fuzzy multi objective linear programming approach, computational algorithm for a scenario when production co-efficient are crisp discrete random variables given. There are three important seasons namely kharif starting from June ending with OctoberNovember, Rabi season starting from November ending with February-March \& Summer season starting March ending with May. For the present study the data has been collected from the department of statistics and economics, revenue etc. and presented as revenue per unit yield of crop, Investment input cost per unit yield of crop, Yield of $i^{\text {th }}$ crop per unit land, Total irrigated land, Total cultivated land, Total availability of water, Maximum possible yield of all crops etc. The data from above source also gives us cost on seeds for $\mathrm{i}^{\text {th }}$ crop per unit area of land, cost on fertilizers for $i^{\text {th }}$ crop per unit area of land, cost on pesticides for $i^{\text {th }}$ crop per unit area of land, cost on Human power for $i^{\text {th }}$ crop per unit area of land, cost on Animal \& Other labor for $\mathrm{i}^{\text {th }}$ crop per unit area of land, cost on Cash rent for $i^{\text {th }}$ crop per unit area of land, cost on land revenue for $i^{\text {th }}$ crop per unit area of land, cost on Unforeseen expenditure for $i^{\text {th }}$ crop per unit area of land, cost on Gross inputs for $i^{\text {th }}$ crop per hectare of land etc. along with their total possible investment of cost. The raw data requires formatting for identification of inputs and the raw statistical data as per the requirements to be incorporated as inputs. After formatting the statistical data we have run the optimal programming problem on LINDO61 Software. We have obtained the optimal section of decision variables on two accounts for obtaining (1) Maximum Production (2) Maximum Profit. The outputs were analyzed with suitable statistical graphs and are placed below.

\section{Step:1}

Solve the one objective function with constraint at time $\mathrm{t}$, using linear programming techniques \& then step by step find the corresponding value of all the objective functions for each of solutions.

\section{Step: 2}

Then find lower bound $Z_{p}^{\prime} \&$ upper bound $Z_{p}^{\prime \prime}$ for each objective functions.

Let $\mu_{p}$ be a linear non decreasing membership function between $Z_{p}^{\prime} \& Z_{p}^{\prime \prime}$, for $\forall p$.

$$
\text { Where } \mu_{p}(x)=\left\{\begin{array}{cl}
1 & \text { if } Z_{P}(x)=Z_{p}^{\prime \prime} \\
\frac{Z_{P}(x)-Z_{p}^{\prime}}{Z_{p}^{\prime \prime}-Z_{p}^{\prime}} \text { if } & Z_{p}^{\prime} \leq Z_{P}(x) \leq Z_{p}^{\prime \prime} \\
0 & \text { if } Z_{P}(x)<Z_{p}^{\prime}
\end{array}\right.
$$

Step: 3

Now transform multiobjective linear programming problem into linear programming problem as $\operatorname{Max} \gamma$

$$
\begin{aligned}
& \mu_{p}(x)=\frac{Z_{P}(x)-Z_{p}^{\prime}}{Z_{p}^{\prime \prime}-Z_{p}^{\prime}} \geq \gamma, x \in X, \\
& \text { Where } Z_{p}(x)=\sum_{j=1}^{n} C_{p j} x_{j}, 0 \leq \gamma \leq 1 \\
& \text { i.e. } Z_{p}(x)-\gamma\left(Z_{p}^{\prime \prime}-Z_{p}^{\prime}\right) \geq Z_{p}^{\prime} \\
& \text { i.e. } \sum_{j=1}^{n} C_{p j} x_{j}-\gamma\left(Z_{p}^{\prime \prime}-Z_{p}^{\prime}\right) \geq Z_{p}^{\prime} \text {, for } \forall p .
\end{aligned}
$$

It can easily solve by two phase simplex method.

\section{Mathematical formulation of crop production problem}

The objectives of the problem are to maximize the production and profit . The computational algorithm developed above is implemented step by step to find a optimal solution of crop production for Patan district, Gujarat. In this district farmers grow Cotton, Mung, Udad, Sesamum, Bajra in kharif season, Bajara in summer season. Gram, Wheat, Mustard, Castor, Fennel, Cumin, Tur, Potato in rabi season. The land available is 392669 hectare with given labour hours constrains. The labour availability for each season is given to be 220 total mandays. A small farm 


\section{International Journal of Science and Research (IJSR) \\ ISSN (Online): 2319-7064 \\ Index Copernicus Value (2013): 6.14 | Impact Factor (2015): 6.391}

holder needs at least $400 \mathrm{~kg}$ of wheat, $200 \mathrm{~kg}$ of Bajara and $40 \mathrm{~kg}$ of Mung for his annual food grains requirement. The problem of the framer is to plan a suitable crop combination model for his land to get maximum profit and aspiration level of rupees 175000 is set to meet his other annual family requirement. The objectives of the problems are to maximize profit and production to provide minimum food grain requirement.

\begin{tabular}{|c|c|c|c|}
\hline $\begin{array}{c}\text { Crop } \\
\text { (variable) }\end{array}$ & $\begin{array}{c}\text { Labour } \\
\text { (manday/ha) }\end{array}$ & $\begin{array}{c}\text { Production } \\
\text { (Kg. /ha. })\end{array}$ & $\begin{array}{c}\text { Return } \\
\text { (Rs. /ha. })\end{array}$ \\
\hline Cotton $\left(x_{1,1}\right)$ & 189 & 992 & 32119 \\
\hline Mung $\left(x_{1,2}\right)$ & 39 & 481 & 5894 \\
\hline Udad $\left(x_{1,3}\right)$ & 31 & 745 & 2964 \\
\hline Sesamum $\left(x_{1,4}\right)$ & 40 & 421 & 6948 \\
\hline Bajara $\left(x_{1,5}\right)$ & 68 & 497 & 2985 \\
\hline Gram $\left(x_{2,1}\right)$ & 310 & 698 & 1093 \\
\hline Wheat $\left(x_{2,2}\right)$ & 88 & 3238 & 18418 \\
\hline Mustard $\left(x_{2,3}\right)$ & 74 & 1562 & 7485 \\
\hline Castor $\left(x_{2,4}\right)$ & 63 & 1854 & 61067 \\
\hline Fennel $\left(x_{2,5}\right)$ & 57 & 1358 & 116925 \\
\hline Cumin $\left(x_{2,6}\right)$ & 110 & 441 & 36633 \\
\hline Tur $\left(x_{2,7}\right)$ & 13 & 985 & 4046 \\
\hline Potato $\left(x_{2,8}\right)$ & 71 & 23281 & 66853 \\
\hline Bajara $\left(x_{3,1}\right)$ & 76 & 2563 & 5066 \\
\hline
\end{tabular}

Where

$x_{i, j}=$ the land area for cultivation of crop $\mathrm{j}$ in

Season $i(=1,2,3)$ (heaters)

$i=1=$ kharif season, $i=2=$ Rabi season,

$i=3=$ summer season

The objective functions are:

Production:

Maximize $Z_{1}=992 x_{1,1}+481 x_{1,2}+745 x_{1,3}+421 x_{1,4}+$ $497 x_{1,5}+698 x_{2,1}+3238 x_{2,2}+1562 x_{2,3}+1854 x_{2,4}+$ $1358 x_{2,5}+441 x_{2,6}+985 x_{2,7}+23281 x_{2,8}+2563 x_{3,1}$

Profit:

Maximize $Z_{2}=32119 x_{1,1}+5894 x_{1,2}+2964 x_{1,3}+$ $6948 x_{1,4}+2985 x_{1,5}+1093 x_{2,1}+18418 x_{2,2}+$

$7485 x_{2,3}+61067 x_{2,4}+116925 x_{2,5}+36633 x_{2,6}+$

$4046 x_{2,7}+66853 x_{2,8}+5066 x_{3,1}$

Subject to constraints:

Labour:

$189 x_{1,1}+39 x_{1,2}+30 x_{1,3}+40 x_{1,4}+68 x_{1,5} \leq 220$

$310 x_{2,1}+88 x_{2,2}+74 x_{2,3}+63 x_{2,4}+57 x_{2,5}+110 x_{2,6}$

$+13 x_{2,7}+71 x_{2,8} \leq 220$

$76 x_{3,1} \leq 220$

Land:

$x_{1,1}+x_{1,2}+x_{1,3}+x_{1,4}+x_{1,5} \leq 392669$

$x_{2,1}+x_{2,2}+x_{2,3}+x_{2,4}+x_{2,5}+x_{2,6}+x_{2,7}+x_{2,8}$ $\leq 392669$

$x_{3,1} \leq 392669$

Food requirements:

$3238 x_{2,2} \geq 400$

$497 x_{1,5}+2563 x_{3,1} \geq 200$

$481 x_{1,2} \geq 40$

Where all $x_{i, j} \geq 0, i=1,2,3 \& j=1$ to 8

Solve this linear programming problem by simplex method for objective function $Z_{1}$

Production $Z_{1}=81816 \mathrm{~kg}$.

Production $Z_{1}=48567 \mathrm{~kg}$

Profit $Z_{2 .}=362020 R s$.

\begin{tabular}{|l|l|}
\hline$x_{1,2}$ & 0.083160 ha. land for Mung \\
\hline$x_{1,3}$ & 7.225225 ha. land for Udad \\
\hline$x_{2,2}$ & 0.123533 ha. land for Wheat \\
\hline$x_{2,8}$ & 2.945480 ha. land for Potato \\
\hline$x_{3,1}$ & 2.894737 ha. land for Bajara \\
\hline
\end{tabular}

Profit $\left(Z_{2}\right)_{1}=235760 \mathrm{Rs}$.

Similar process is applied for objective function $Z_{2}$.

Profit $Z_{2 .}=484071 R s$

\begin{tabular}{|l|l|}
\hline$x_{1,2}$ & 0.083160 ha. land for Mung \\
\hline$x_{1,4}$ & 5.418919 ha. land for Sesamum \\
\hline$x_{2,2}$ & 0.123533 ha. land for Wheat \\
\hline$x_{2,5}$ & 3.668931 ha. land for Fennel \\
\hline$x_{3,1}$ & 2.894737 ha. land for Bajara \\
\hline
\end{tabular}

Production $\left(Z_{1}\right)_{2}=15123 \mathrm{~kg}$.

Positive Ideal Solution:

\begin{tabular}{|c|c|c|}
\hline & $Z_{1 .}$ & $Z_{2 .}$ \\
\hline$Z_{1 .}$ & $81816=Z_{1}^{\prime \prime}$ & $235760=Z_{2}^{\prime}$ \\
\hline$Z_{2 .}$ & $15123=Z_{1}^{\prime}$ & $484071=Z_{2}^{\prime \prime}$ \\
\hline
\end{tabular}

The problem is converted into following form (by step: 3 ) Maximize $\gamma$

Such that

\section{Labour:}

$189 x_{1,1}+39 x_{1,2}+30 x_{1,3}+40 x_{1,4}+68 x_{1,5} \leq 220$

$310 x_{2,1}+88 x_{2,2}+74 x_{2,3}+63 x_{2,4}+57 x_{2,5}+110 x_{2,6}$ $+13 x_{2,7}+71 x_{2,8} \leq 220$

$76 x_{3,1} \leq 220$

Land:

$x_{1,1}+x_{1,2}+x_{1,3}+x_{1,4}+x_{1,5} \leq 392669$

$x_{2,1}+x_{2,2}+x_{2,3}+x_{2,4}+x_{2,5}+x_{2,6}+x_{2,7}+x_{2,8}$ $\leq 392669$

$x_{3,1} \leq 392669$

Food requirements:

$3238 x_{2,2} \geq 400$

$497 x_{1,5}+2563 x_{3,1} \geq 200$

$481 x_{1,2} \geq 40$

\section{Production:}

$992 x_{1,1}+481 x_{1,2}+745 x_{1,3}+421 x_{1,4}+497 x_{1,5}+698 x_{2,1}+$ $3238 x_{2,2}+1562 x_{2,3}+1854 x_{2,4}+1358 x_{2,5}+441 x_{2,6}+$ $985 x_{2,7}+23281 x_{2,8}+2563 x_{3,1}-66693 \gamma \geq 15123$

Profit:32119 $x_{1,1}+5894 x_{1,2}+2964 x_{1,3}+6948 x_{1,4}+$ $2985 x_{1,5}+1093 x_{2,1}+18418 x_{2,2}+7485 x_{2,3}+61067 x_{2,4}+$ $116925 x_{2,5}+36633 x_{2,6}+4046 x_{2,7}+66853 x_{2,8}+5066 x_{3,1}-$ $248311 \gamma \geq 235760$

Where all $x_{i, j} \& \gamma \geq 0, i=1,2,3 \& j=1$ to 8

Solving this linear programming using LINDO61, the result for the optimal crop planning model for area of different crops (in hacters) is as following:

\begin{tabular}{|l|l|}
\hline$x_{1,2}$ & 0.083160 ha. land for Mung \\
\hline$x_{1,4}$ & 5.418919 ha. land for Sesamum \\
\hline$x_{2,2}$ & 0.123533 ha. land for Wheat \\
\hline$x_{2,5}$ & 1.739369 ha. land for Fennel \\
\hline$x_{2,8}$ & 1.549085 ha. land for Potato \\
\hline$x_{3,1}$ & 2.894737 ha. land for Bajara \\
\hline
\end{tabular}

$\gamma=0.50146$ 


\section{International Journal of Science and Research (IJSR) ISSN (Online): 2319-7064}

Index Copernicus Value (2013): 6.14 | Impact Factor (2015): 6.391

\section{Discussion}

\begin{tabular}{|c|c|c|c|c|c|c|c|c|c|c|}
\hline \multicolumn{11}{|c|}{ Crop Combination Planning } \\
\hline \multirow{2}{*}{ Season } & \multirow{2}{*}{$\begin{array}{c}\text { Farmsize in } \\
\text { Crop ha. }\end{array}$} & \multirow{2}{*}{$\begin{array}{c}\text { Marginal } \\
\text { Below } 1.0\end{array}$} & \multirow{2}{*}{$\begin{array}{c}\text { Small } \\
1.0 \text { to } 1.99\end{array}$} & \multicolumn{2}{|c|}{ Semi Medium } & \multicolumn{3}{|c|}{ Medium } & \multicolumn{2}{|c|}{ Large } \\
\hline & & & & 2.0 to 2.99 & 3.0 to 3.99 & 4.0 to 4.99 & 5.0 to 7.49 & 7.5 to9.99 & 10to11.99 & 12 \&above \\
\hline \multirow{3}{*}{ Kharif } & Mung & 0.083160 & 0.083160 & 0.083160 & 0.083160 & 0.083160 & 0.083160 & 0.083160 & 0.083160 & 0.083160 \\
\hline & Wheat & 0.123533 & 0.123533 & 0.123533 & 0.123533 & 0.123533 & 0.123533 & 0.123533 & 0.123533 & 0.123533 \\
\hline & Fennel & 0.26 to 0.88 & 0.88 to 1.87 & 1.88 to 2.87 & 2.88 to3.87 & 3.88 to 4.87 & 4.88 to 7.37 & 7.38to9.87 & 9.88to11.87 & 11.88\&above \\
\hline \multirow{7}{*}{ Rabi } & Potato & 0.26 to 0.88 & 0.88 to 1.87 & 1.88 to 2.87 & 2.88to3.87 & 3.88to4.87 & 4.88to 7.37 & 7.38to9.87 & 9.88to11.87 & 11.88\&above \\
\hline & Wheat & 0.123533 & 0.123533 & 0.123533 & 0.123533 & 0.123533 & 0.123533 & 0.123533 & 0.123533 & 0.123533 \\
\hline & Fennel & 0.5258802 & 0.50 to 1.00 & 0.33 to 1.32 & 1.33 to 2.32 & 2.33 to 3.32 & 3.33 to 5.82 & 5.83 to 8.32 & 8.33to 10.32 & 10.33\&above \\
\hline & Potato & 0.3505868 & 0.40 to 0.87 & 1.54908 & 1.54908 & 1.54908 & 1.54908 & 1.54908 & 1.54908 & 1.54908 \\
\hline & Wheat & 0.123533 & 0.123533 & 0.123533 & 0.123533 & 0.123533 & 0.123533 & 0.123533 & 0.123533 & 0.123533 \\
\hline & Fennel & 0.3505868 & 0.40 to 0.87 & 1.739369 & 1.739369 & 1.739369 & 1.739369 & 1.739369 & 1.739369 & 1.739369 \\
\hline & Potato & 0.5258802 & 0.50 to 1.00 & 0.14 to 1.13 & 1.14 to 2.13 & 2.14 to 3.13 & 3.14 to5.63 & 5.64to8.13 & 8.14to 10.13 & 10.14\&above \\
\hline Summer & Bajara & 1.0 & 1.0 to1.99 & 2.0 to 2.99 & 3.0 to 3.99 & 4.0 to 4.99 & 5.0 to 7.49 & 7.5 to9.99 & 10to11.99 & 12 \&above \\
\hline
\end{tabular}

The present study shows that, marginal farm 0holders can get $3466 \mathrm{~kg}$ to $23854 \mathrm{~kg}$. production, small farm holders can get $3743 \mathrm{~kg}$. to $30807 \mathrm{~kg}$. production, semi medium farm holders can get $8888 \mathrm{~kg}$.to $51527 \mathrm{~kg}$. production, medium farm holders can get $17572 \mathrm{~kg}$. to $90528 \mathrm{~kg}$. Production \& large farm holders can get $274383 \mathrm{~kg}$. and above crop production of various crops during whole year.

In Patan district, most of farmers are semi middle and middle farm holders. On the other hand land constraints has a very important role in determining the optimal model. According to results farmer can get profit of Rs.362020 which is more than his aspiration level. Also a farmer can achieve maximum production and plan his course of action on multiobjective task. The application of fuzzy concept in cropping pattern for high economic expectations has successfully tackled the uncertainty and imprecision in profits and production.

\section{References}

[1] H. J. Zimmermann, "Fuzzy programming and linear programming with several objective functions", Fuzzy Sets and Systems, 1(1978), pp. 45-55

[2] H. J. Zimmermann, "Fuzzy mathematical programming", Computers and Operations Research, 10 (1983), pp. 291298

[3] M. Sakawa, H. Yano, T. Yumine, "An interactive fuzzy satisficing method for multiobjective linear-programming problems and its Application" IEEE Transactions on Systems, Man, and Cybernetics, 17 (1987), pp. 654-661

[4] R. Slowinski, "A multi criteria fuzzy linear programming method for water supply system development planning", Fuzzy Sets and Systems, 19(1986), pp. 217-237

[5] S. B. Sinha, K. A. Rao, and B. K. Mangaraj, "Fuzzy goal programming in multicriteria decision systems- A case study in agriculture planning", Socio -Economic Planning Sciences, 22(2) (1988), pp. 93-101

[6] A. sher and I. Amir, "Optimization with fuzzy constraints in agriculture production planning", Agricultural systems. 45 (1994), pp. $421-441$.

[7] J. M. Sumpsi, Fransisco Amador, Carlos Romero, "On farmer's objectives: A multi criteria approach", Europian Journal Of Operation Research. 96(1996), pp. 64-71.
[8] R. A. Sarker, S. Talukdar and A. F.M. Anwarul Haque, "Determination of optimum crop mix for crop cultivation in Bangladesh", Applied Mathematical Modelling, 21(1997), pp. 621-632.

[9] B. B. PAL, B. M. Moitra, "Fuzzy goal programming approach to long term land allocation planning in agricultural system: A case study", Proceedings of fifth international conference on Advances in pattern recognition, Allied publishers Pvt. Ltd.( 2003), pp.441447.

[10] P. M. Vasant, "Application of fuzzy linear programming in production planning", Fuzzy Optimization and Decision Making, 3(2003), pp. 45-55.

[11] A. Biswas, B. B. Pal, "Application of fuzzy goal programming technique to land use planning in agricultural system", Omega, 33(2005), pp. 391-398.

[12] W. Lodwick, D. Jamison and S. Russell, "A comparison of fuzzy stochastic deterministic methods in linear programming", Proceeding of IEEE, (2000), pp. 321-325.

[13] T. Itoh, H. Ishii, T. Nanseki, "Amodel of crop planning under uncertainty in agriculture management", Int .J. Production Economics, 81-82(2003), pp. 555-558.

[14] T. Toyonaga, T. Itoh, H. I shii, "A crop planning problem with fuzzy random profit coefficients", Fuzzy Optimization and Decision Making, 4(2005), pp.51-59.

[15] A.Garg, S. R. Sinh, "Optimization under uncertainty in agricultural production planning", I concept pocket journal: Computational Intelligence for Financial Engineers, 1(2010), pp. 1-12.

[16] M. Sakawa and H.Yano, "Interactive fuzzy decision making for multiobjective nonlinear programming using augmented minimax problems", Fuzzy Sets and Systems, 20(1986), pp.31-43.

[17] S. Chanas, "Fuzzy programming in multiobjective linear programming-A parametric approach", Fuzzy Sets and Systems, 29(1989), pp.303-313. 